\title{
Correlation between Chronological Age, Cervical Vertebral Maturation and Fishman's Skeletal Maturity Indicators in Central India Population
}

\author{
Dr Natasha Patil,' Dr Neha Maheshwari, ${ }^{2}$ Dr Rohit Sharma, ${ }^{3}$ Dr Shashank Soni, ${ }^{4}$ Dr Ashish Kushwah' \\ 'Senior Lecturer, Department of Orthodontics, M.P.C.D \& R.C. Gwalior, ${ }^{2}$ Private practitioner, Nanda Dental Care, \\ 3Senior Lecturer, Department of Prosthodontics, 4Post Graduate Student, Department of Orthodontics, \\ M.P.C.D \& R.C. Gwalior,

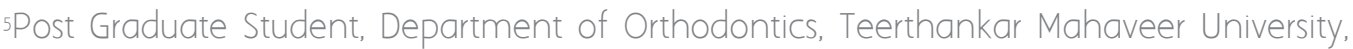

\section{ABSTRACT}

Introduction: Skeletal maturity indicators are very important indicators when diagnosing and panning the treatment in growing population. Cervical Vertebrae Method( CVM) and Fishman's Skeletal Maturity Indicators are two commonly used methods for the diagnosis and treatment planning. The aim of the study was to investigate the correlation between cervical vertebral maturation (CVM)and Fishman'shand-wrist skeletal maturity indicator and chronological age by including subjects within the range of circumpubertal growth spurt in Central India.

Materials \& Method: One Twenty Five contemporary hand-wrist and lateral cephalometric radiographs from population of Central India were randomly selected and analyzed. All subjects were within the circumpubertal period i.e. female subjects were between 10 and 15 years of age, and the male subjects were between 12 and 17 years of age. The hand-wrist bone analysis was evaluated using the method developed by Fishman whereas cervical vertebra bone analysis was evaluated using the method developed by Baccetti and coworkers. These two methods and chronological age were correlated using the Spearman rank correlation analysis.

Result: CVM was significantly correlated with hand-wrist maturation ( $r=0.8868)$. However low correlation was found between the CVM and chronological age ( $r=0.7139)$ and little correlation was found between the HWM and chronological age ( $r=0.6892)$.

Conclusion: CVM is a valid indicator of skeletal growth during the circumpubertal growth period and has a high correlation with the HWM for the Central India population. Howeverchronological ageis not suitable to measure skeletal maturity as shown by the low correlations found between the chronological age and both CVM and HWM.

Keywords: Cervical vertebra maturation, Chronological age, Hand-wrist maturation, Skeletal maturity.

\section{INTRODUCTION}

The issue of optimal timing in dentofacial orthopedicsis intimately related to identification of periods of acceleratedgrowth that contribute significantly in correction of skeletal imbalances in individual patient.

Several clinical studies have shown that the greatest response to functional jaw orthopedics tends to occur during circumpubertal growth period.' Before maximal pubertal growth the skeletal response were less in subjects as well as after maximal pubertal growth. ${ }^{2.3}$

Therefore, to assess growth spurts for the determination of the optimal growth modification treatment timing a biologic indicators series were used.These methods includes characteristics of sexual maturation, facial growth and peak height velocities, chronological age, dental development, body weight,body height and handwrist maturity. ${ }^{4}$

Successful growth modification in orthodontics is dependent on skeletal maturation.5 Hand wrist maturation (HWM) analysis is the most widly used and a classical method for evaluation of skeletal age. HWM is the highly reliable method done by radiograph. However, an addition exposure of ionizing radiation of the orthodontic patient required to the routine radiographic records for this analysis. ${ }^{6}$ 
The assessment of the degree of cervical vertebral maturation (CVM) is anothermethod of assessingskeletal maturation. In case of CVM assessment lateral cephalometric radiograph is needed which is routinely taken for orthodontic treatment planning so no need of any extra ionizing radiation exposure required .?

Lamparski studied the development of the cervicalvertebrae and demonstrated the efficacy of the CVM method in assessing skeletal age. ${ }^{8}$ The use of a lead collar to protect the thyroid mayhinder full vision of the cervical spine. In 1995, Hassel and Farman compiled a new index of CVM, which evaluated the visible lateral profiles of the $2 \mathrm{nd}, 3 \mathrm{rd}$, and 4 th cervical vertebrae.9 In 2002, Baccetti et al devisedthe CVM method that we applied in our study.

In previous studies subjects with wide age range were included ( between 5 year to 18 years) forcorrelation of the CVM methodwith skeletal maturity.10So due to the wide age range of subjects inclusion before and after the pubertal growth spurt correlation coefficient may be affected.Therefore, in this study we investigated the correlationof the CVM and HWM byincluding near or within the pubertalgrowth spurtsubjects, using the Central India as a studypopulation.

\section{MATERIALS AND METHOD}

One Twenty Five hand-wrist and lateral cephalometric radiographs of patient who reported to, Department of Orthodontics and Dento-facial Orthopedics at Maharana Pratap College of Dentistry and Research Centre, Gwalior (M.P) were selected.

The subjects selected for study were based on the

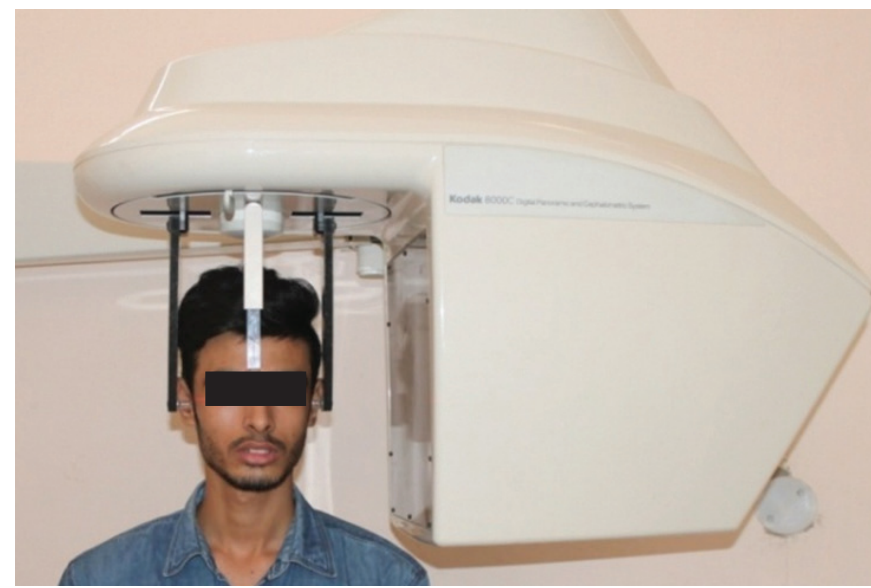

Figure 1: Kodak $8000 \mathrm{C}$ Digital Panoramic and Cephalometric System is used to take the lateral cephalogram following inclusion and exclusion criteria.

\section{Inclusion Criteria}

The selection criteria of the subjects are as follows:

- The radiograph is taken within the circumpubertal period; with female age range 10 to 15 years and male age range 12 to 17 years.

- The bones should appear clearly and should have been unaffected by systemic disease.

- Cephalograms showing all first four vertebrae clearly.

- The hand-wrist radiograph is of left hand.

\section{Exclusion Criteria}

- $\quad$ Patient with facial asymmetry.

- Patients with history of trauma and surgery in dentofacial region.

- Patient with congenital abnormalities affecting growth and development and traumatic lesions of cervical vertebrae.

- $\quad$ Patient suffering from systemic disease.

Kodak 8000C Digital Panoramic and Cephalometric System is used to take the lateral cephalogram and hand wrist radiograph. Radiographs of high quality and good contrast were used. The CVM was evaluated using the method developed by Baccetti and coworkers (Fig.1). The hand-wrist maturation (HWM) of the same patient was evaluated using the Fishman's method (Fig.2).

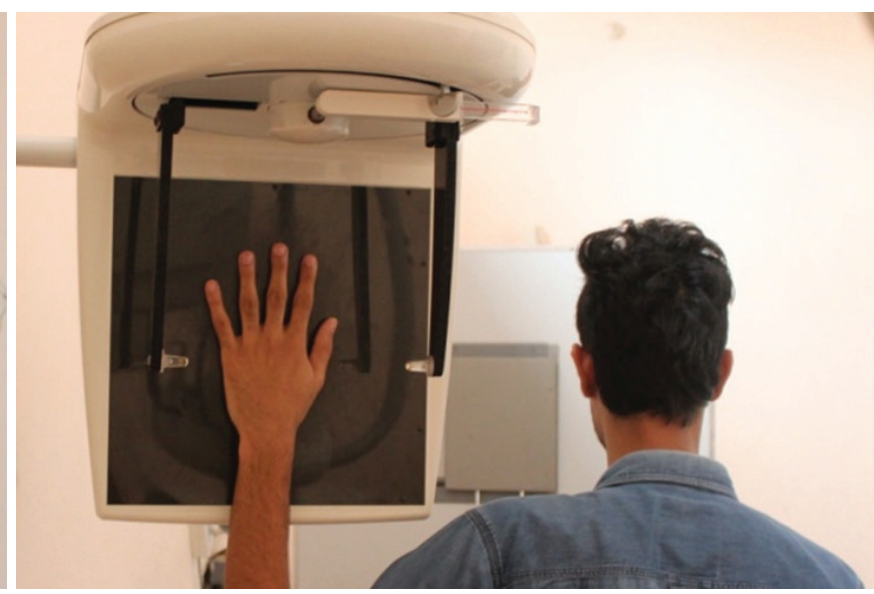

Figure 2: Kodak $8000 \mathrm{C}$ Digital Panoramic and Cephalometric System is used to take the hand wrist radiograph 


\section{Statistical Analysis}

The skeletal maturity indicator (SMI) scores and cervical vertebrae maturity indicator (CVMI) scores were obtained and analyzed with reference to chronological age. The SMI and CVMI were compared with each other and with chronological age and their correlation was established statistically by using Spearman rank correlation coefficient.

\section{Method Errors}

The intraexaminer error was calculated for 25 patients. Randomly selected lateral cephalometric and handwrist radiographs for both methods were evaluated by the investigator and then reevaluated by the same investigator after 3 weeks. 20 of 25 interpretations were the same at the second examination. The method error was insignificant. The Kappa statistic for concordance was 0.811 .

\section{RESULT}

Correlation between CVMI and HWM (SMI) (Graph 1)

This study shows that CVM (CS) was significantly correlated with HWM (SMI) (Spearman $r=0.8868$ and r2 $=0.786$ ). The correlation plot appeared linear. There was a linear relationship between the CVM (CS) and the HWM (SMI). This indicates that the eleven discrete stages of SMI can be confidently correlated to corresponding 6 stages of CVMI.

Correlation between CVMI and Chronological Age (Graph 2)

There was low correlation between the CVM (CS) and

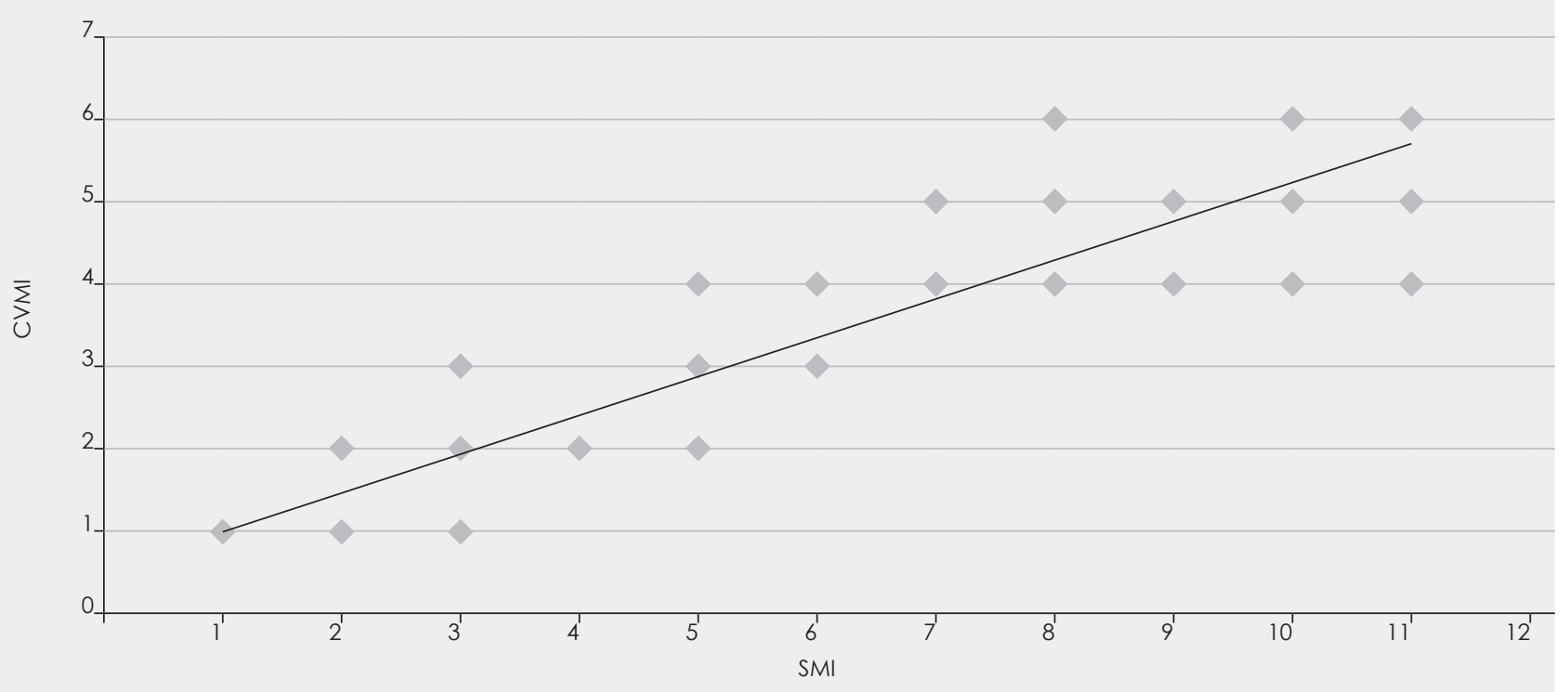

Graph 1: Bar graph representing correlation coefficient between SMI and CVMI at different age group

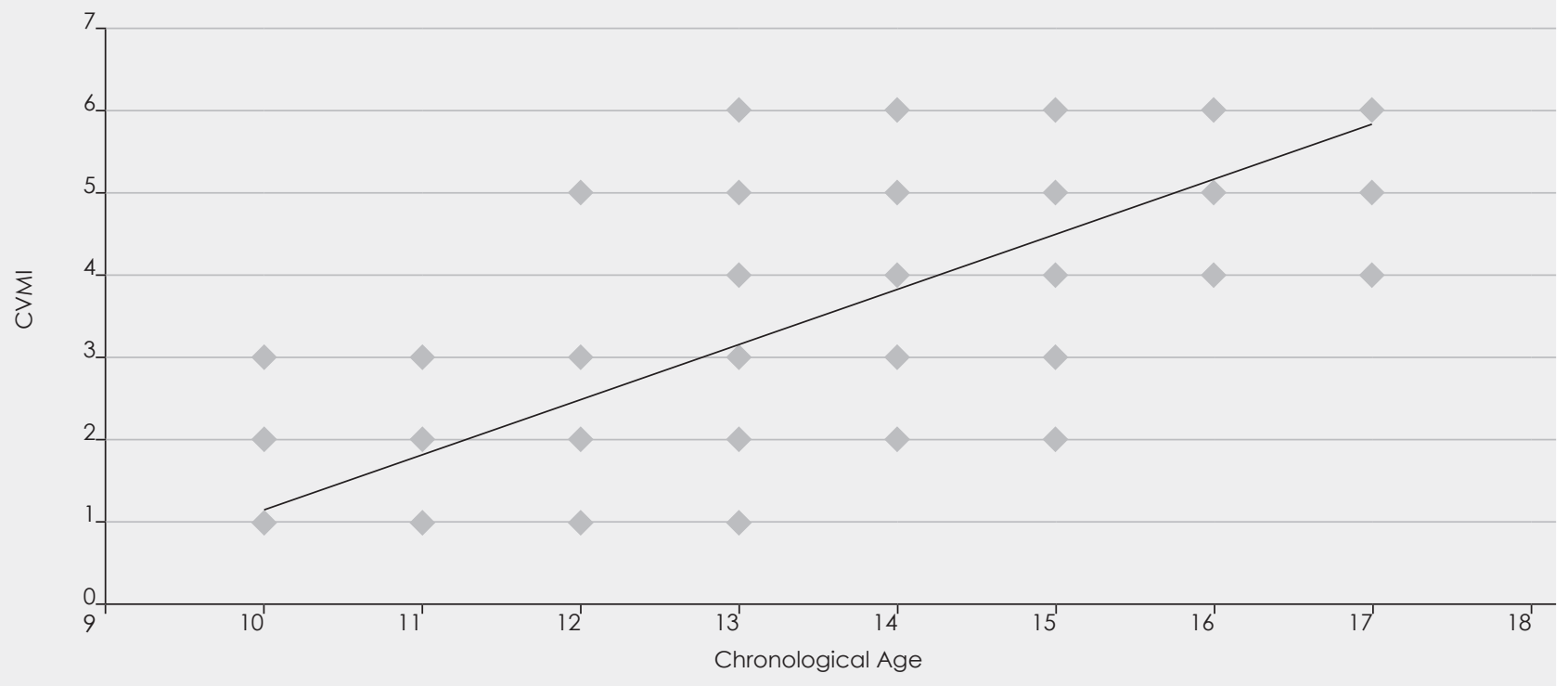

Graph 2: Bar graph representing correlation coefficient between CVMI and Chronological age at different age group 


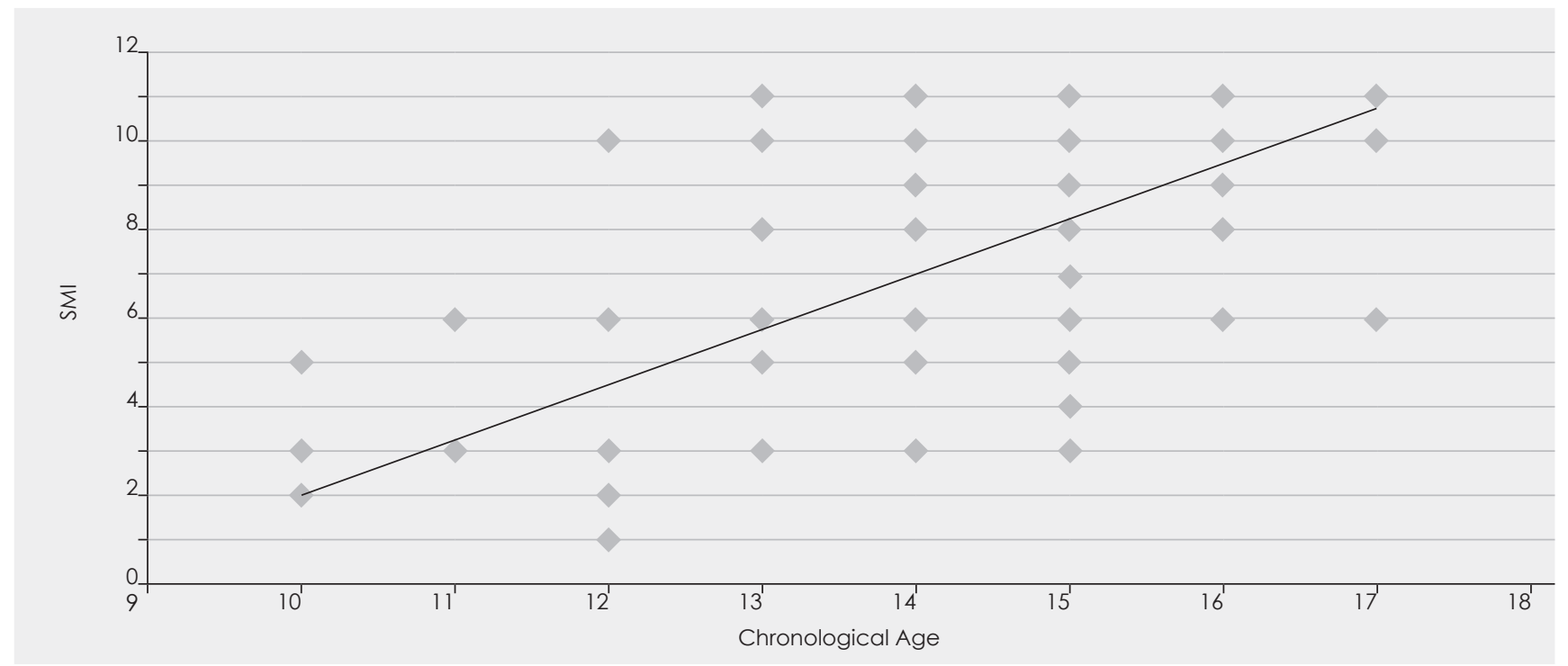

Graph 3: Bar graph representing correlation coefficient between SMI and Chronological age at different age group

chronological age (Figures 3 and 4). The correlation plots appeared scattered widely (Spearman $r=0.7139$ and $\mathrm{r} 2=0.5096$ ).

Correlation between SMI and Chronological Age (Graph 3)

There was little correlation between the HWM (SMI) and chronological age (Figures 5 and 6). The correlation plots appeared scattered widely (Spearman $r=0.6892$ and $\mathrm{r} 2=0.4749$ ).

\section{DISCUSSION}

The finding of present study indicates that hand wrist bone analysis and cervical vertebral maturation analysis are sensitive and precise in evaluating skeletal maturity within circumpubertal period.

It has been demonstrated clearly that the evaluation of individual skeletal maturity is fundamental in dentofacial orthopedics, as the greatest effects of functional/orthopedic appliances occur when the peak in mandibular growth is included in the treatment period. " Hence different age ranges for different sexes were selected as subjects for this study because of the difference in the onset of the circumpubertal periods between boys and girls.

The high correlation obtained between the CVM method and the HWM method in this applies to the Central India population. This study was the first study of the CVM and the HMW methods performed in this population. This is in accordance with the study conducted by Paola Gandini et al (2006) ${ }^{6}$ and Hessa Abdulla Alkhala et al (2008). ${ }^{4}$ However further studies are needed to evaluate the correlation between these indicators in other ethnic groups within circumpubertal period.

For clinicians wishing to start orthopedic treatment, continuous monitoring of the skeletal maturity using hand wrist films may not be necessary. Instead, they can monitor the changes in the shape and inferior border curvature of the cervical vertebrae as seen on the routinely taken lateral cephalogram which could be more easily interpreted and readily available and acceptable.

Sziska and Pancherz ${ }^{12}$ attempted to ascertain if analysis of C3 cervical vertebrae development is reliable and valid in the assessment of skeletal and somatic maturity. They found that the $\mathrm{C} 3$ analyzing method has high reliability and validity and can replace the hand radiograph approach in the assessment of skeletal and somatic maturity.

This study also reveals that the low correlations found between the chronological age and CVM and the chronological age and HWM showed that chronological age was not suitable to measure skeletal maturity.

\section{CONCLUSION}

The CVM method shows high correlation with the HWM method in the central India population.

Low correlations were found between chronological age and HWM, and between chronological age and CVM in the central India population. 


\section{REFERENCES}

1. Baccetti T., Fanchi Lorenzo, McNamara J.A. An improved version of cervical vertebral maturation (CVM) method for the assessment of mandibular growth. Angle. Orthod 2002; 72: 316-323.

2. Hagg U., Taranger J. Skeletal stages of the hand and wrist as indicators of the pubertal growth spurt. Acta.Odontol.Scand.1980; 38: 187200

3. Ha"gg U, Taranger J. Menarche and voice change as indicators of pubertal growth spurt. ActaOdontol Scand. 1980; 38:179-186

4. Hessa Abdulla Alkhala; Ricky W. K. Wongb; A. Bakr M. Rabiec Correlation between chronological age, cervical vertebral maturation and fishman's skeletal maturity indicators in southern chineseAngle Orthodontist, Vol 78, No 4, 2008.

5. Mir C.F., Mauricio F.R., Orellana M.F., Major P.W. Association between growth stunning with dental development and skeletal maturation stage. Angle Orthod.2005, 75: 935-940.

6. Paola Gandinia; Marta Mancinib; Federico Andreani. A Comparison of hand-wrist bone and cervical vertebral analyses in measuring skeletal maturation. Angle Orthodontist, Vol 77, No 6, 2006

7. Al KhalHA, Wong RWK, Rabie ABW. Elimination of hand wrist radiographs for maturity assessment in children needing orthodontic therapy. Skeletal Radiol 2008;2008;37:195-200

8. Lamparski DG. Skeletal age assessment utilizing cervical vertebrae [Master of Science dissertation]. Pittsburg, Pa:The University of Pittsburg; 1972.

9. Hassel B, Farman AG. Skeletal maturation evaluation using cervical vertebrae. Am J OrthodDentofacOrthop. 1995; 107:58-66

10. Garcia Fernandez P., Torre H., Flores L.I. Rea. The cervical vertebrae as maturational indicators.J.C.0.1998; 32: 221-225.

11. Franchi L., Baccetti T., MCNamara Jr. J.A. Mandibular growth as related to cervical vertebral maturation and body height. Am J.Orthod. DentofacialOrthop 2000; 118: 335-340.

12. Szyska M, Pancherz H. The cervical vertebrae (C3) in skeletal and somatic maturation evaluation. Eur J Orthod. 1999; 21:624. 